\title{
Two Aspects of Alien Species Management in a Seaport: Ship Classification and Ship Inspection Costs ${ }^{\dagger}$
}

\author{
Amitrajeet A. BATABYAL*
}

\begin{abstract}
The many aspects of alien species management normally all involve decision making over time and under uncertainty. Therefore, in this note, we focus on an arbitrary seaport in a country called Home and we conduct a dynamic and stochastic analysis of two questions that have received insufficient attention in the extant literature on alien species management. First, we provide a particular way of classifying ships that enter the Home seaport from $K$ possible countries in the time interval $[0, t]$. Second, we characterize the total cost of inspecting the ships that arrive in the Home seaport during the same time interval $[0, t]$.
\end{abstract}

JEL Classification: F180, Q200, Q560

Keywords: Alien Species, Classification, Inspection Cost, Management, Uncertainty

\section{Introduction}

The volume of international trade between countries has increased significantly over time, in part because of the phenomenon that we now call globalization. Maritime trade is a large fraction of the world's total trade and the work of Levinson (2006) clearly tells us that in contemporary times, ships are commonly used to carry an assortment of internationally traded goods between countries. International trade in goods between countries is typically beneficial to the countries involved. Even so, as Levine and D'Antonio (2003), Batabyal et al. (2005), Work et al. (2005), Batabyal and Lee (2006), DeAngelo et al. (2007), and Batabyal (2008) have noted, today, there is increasing worry that in addition to dispatching goods between countries, by means of their container cargo and their ballast water, ships are also accidentally transporting all kinds of alien (also known as exotic or invasive or non-native) animal and plant species from one region of the world to another. ${ }^{1}$

The discharge of ballast water by ships is frequently responsible for the accidental introductions of alien species in a particular region of the world. As a rule, cargo ships carry ballast water in order to enhance maneuverability and stability when they are not carrying full loads. When these ships come into a seaport, this ballast water must be discharged before cargo can be loaded. Batabyal (2006, 2008) tells us that over 4,000 species of algae, invertebrates, and other marine organisms are being moved around the world in ship ballast tanks on a daily basis. These alien

+ I thank Yoshiro Higano and two anonymous referees for their helpful comments on a previous version of this paper. In addition, I acknowledge financial support from the Gosnell endowment at RIT. The usual disclaimer applies.

* Department of Economics, Rochester Institute of Technology, 92 Lomb Memorial Drive, Rochester, NY 14623-5604, USA. Internet aabgsh@ rit.edu

Received: 26 February 2008 Accepted : 4 October 2008

(C) 日本地域学会 (JSRSAI) 2008

${ }^{1}$ In addition to container cargo and the ballast water of ships, very generally, alien species can be transported from one region of the world to another when these species "hitch rides" on ships, trains, trucks, and airplanes. With regard to container cargo, alien species may hide in crates or be present in the commodities being transported. 
species have frequently invaded their novel habitats and the ensuing biological invasions have turned out to be very costly for the countries in which these novel habitats are located. For the United States alone, the magnitude of these costs is staggering. In this connection, the Office of Technology Assessment (OTA (1993)) informs us that the Russian wheat aphid caused approximately $\$ 600$ million worth of crop damage between 1987 and 1989. Along the same lines, Pimentel et al. (2000) have estimated the total costs of all alien species to be around $\$ 137$ billion per year.

Alien species have caused not only economic damage but a great deal of ecological damage as well. The work of Vitouselk et al. (1996) and de Wit et al. (2001) is relevant here. These investigators have noted that alien species can diminish biological diversity, change ecosystem processes, and act as vectors of diseases. As an example, Cox (1993) has noted that out of 256 vertebrate extinctions with an acknowledged cause, 109 are the outcome of the actions of alien species. Even a single alien species can give rise to great damage. Savidge (1987) tells us that subsequent to an invasion of Guam by the brown tree snake, all twelve of this island' bird species became extinct.

What we have been saying in the previous three paragraphs leads to the followingstraightforward conclusion: alien species can be and often have been a great menace to society. Therefore, investigators have now begun to analyze the subject of alien species management in an organized manner. Perrings (2005) has delineated alien species problems in terms of the stochastic processes they induce and he has then gone on to study the effects of mitigation and adaptation strategies. Batabyal and Nijkamp (2007) have calculated the total number of biological invasions in a particular time period and they have used this result to compute the total dollar damage from biological invasions in this same time period. Finoff et al. (2007) have shown that if alien species managers act as though they are risk averse then their caution can backfire when it results in less prevention and more control. Hence, they reason that social welfare is highest when managers are willing to take risks with prevention. Mehta et al. (2007) have remarked that the most desirable alien species detection strategy depends primarily on the ease of detection and the biological relationships of each distinct alien species. Finally, in the paper that is most closely related to this note, Batabyal (2008) has, inter alia, computed the arrival rate functions of ships entering a seaport in a country called Home from $N$ potential countries when the individual ship arrival rates can fluctuate over time.

Our understanding of regulatory issues in the context of alien species management has certainly been enhanced by the papers discussed in the preceding paragraph. Even so, there are several questions involving decision making over time and under uncertainty that have received insufficient attention in the extant literature on alien species management. Therefore, in this note, we focus on an arbitrary seaport in a country called Home and we conduct a dynamic and stochastic analysis of two hitherto largely unstudied questions concerning alien species management. ${ }^{2}$ In particular, following the recent work of Batabyal $(2006,2008)$ and Costello et al. (2007), we first concentrate on a particular time interval, say $[0, t]$ and then we provide a specific way of classifying ships that enter the Home seaport from $K$ potential countries. Next, for the same time interval $[0, t]$, we characterize the total cost of inspecting ${ }^{3}$ the various ships that arrive in the Home seaport.

The rest of this note is organized as follows. Section 2 first describes the Poisson process and then it uses the theory of Poisson processes ${ }^{4}$ to provide a particular way of classifying ships that

2 The reader should understand that this contribution of ours is a note that analyzes two specific questions. In particular, this note is not a full-length paper and hence we shall not be conducting an exhaustive analysis of the many and varied aspects of alien species management here.

${ }^{3}$ As noted in Batabyal (2008), in the United States, the Department of Agriculture' Animal and Plant Health Inspection Service (APHIS) frequently uses inspections to screen arriving ships at seaports for alien species.

${ }^{4}$ See Ross (1996, chapter 2) and Tijms (2003, chapter 1) for textbook accounts of the Poisson process. 
enter the Home seaport from $K$ potential countries in the time interval $[0, t]$. Next, section 3 first describes compound Poisson random variables and processes and then it determines the total cost of inspecting the ships that arrive in the Home seaport during the same time interval $[0, t]$. Finally, section 4 concludes and discusses ways in which the research in this note might be extended.

\section{A Ship Classification Scheme}

\subsection{The Poisson process}

A counting process $\{Y(t): t \geq 0\}$ is said to be a Poisson process with rate $\lambda>0$ if the times between successive counts $Z_{1}, Z_{2}, Z_{3}, \cdots$ have a common exponential cumulative distribution function such that $\operatorname{Prob}\left\{Z_{n} \leq z\right\}=1-e^{-\lambda z}$ for $z \geq 0$. Because the exponential distribution is memoryless, ${ }^{5}$ the Poisson process is often said to possess the Markovian property. We now proceed to our classification scheme for the various ships that enter the Home seaport from $K$ potential countries in the interval $[0, t]$.

\subsection{The model}

Suppose that a seaport manager-responsible for controlling the unintentional introductions of alien species in Home-is observing ships enter the Home seaport from various countries. During the time period of interest $[0, t]$, ships arrive in the seaport under study in accordance with a stationary Poisson process with rate $\lambda>0$. Each arriving ship is classified as being from country $j$ where $j=1, \cdots, K$. Further, if a ship arrives at time $s$, then, independently of other arrivals, it is classified as a country $j$ ship with probability $P_{j}(s) \geq 0, j=1,2, \cdots K$. Obviously, we have $\sum_{j=1}^{K} P_{j}(s)$ $=1$.

In order to arrive at our ship classification scheme, let $M_{j}(t)$ denote the number of country $j$ ships that have arrived in the Home seaport in the time interval $[0, t]$. We now want to demonstrate that the $M_{j}(t), j=1, \cdots, K$ are independent and that the number of ships from country $j$ arriving in the Home seaport in the interval $[0, t]$ is Poisson distributed with mean $\lambda \int_{0}^{t} P_{j}(s) d s$. We begin by computing $\operatorname{Prob}\left\{M_{j}(t)=m_{j}, j=1, \cdots, K\right\}$. Because of the Poisson structure of our model, we can tell that

$$
\operatorname{Prob}\left\{M_{j}(t)=m_{j}, \quad j=1, \cdots, K\right\}=\operatorname{Prob}\left\{M_{j}(t)=m_{j}, j=1, \cdots, K / M(t)=\sum_{j=1}^{K} m_{j}\right\} \frac{e^{-\lambda t}(\lambda t)^{\Sigma^{k} m_{j}}}{\left(\sum_{j=1}^{K} m_{j}\right) !} .
$$

Now given $M(t)=\sum_{j=1}^{K} m_{j}$, by theorem 2.3.1 in Ross (1996, p. 67), the unordered set of ship arrival times are independent and uniformly distributed on the time interval $[0, t]$. With this result and with the application of proposition 2.3.2 in Ross (1996, p. 69) in our context, we reason that the probability that an arbitrary arriving ship in the Home seaport is from country $j$ or $P_{j}=\int_{0}^{t} P_{j}(x) d x / t$ and the conditional probability in equation (1) above is, in fact, the multinomial.

With this information in place, we can now write

$$
\operatorname{Prob}\left\{M_{j}(t)=m_{j}, j=1, \cdots, K\right\}=\frac{\left(\sum_{j=1}^{K} m_{j}\right) !}{m_{1} ! \cdots m_{k} !} P_{1}^{m_{1}} \cdots P_{m_{K}}^{m_{K}} \frac{e^{-\lambda t}(\lambda t)^{\Sigma^{k} m_{j}}}{\left(\sum_{j=1}^{K} m_{j}\right) !} .
$$

The right-hand-side (RHS) of equation (2) can be simplified further to give

$$
\operatorname{Prob}\left\{M_{j}(t)=m_{j}, j=1, \cdots, K\right\}=\prod_{j=1}^{K} e^{-\lambda t P_{j}}\left(\lambda t P_{j}\right)^{m_{j}} / m_{j} ! .
$$

The reader should note that many previous papers have used the Poisson process to study questions in alien species management and, therefore, we are certainly not the first to do so. For a more detailed corroboration of this claim, the reader should consult Costello and McAusland (2003), Batabyal and Nijkamp (2007), DeAngelo et al. (2007), and Batabyal (2008).

${ }^{5}$ See Ross (1996, pp. 37-38) and Tijms (2003, pp.2-5) for more on the memoryless property of the exponential distribution. 
Equation (3) gives us our basic ship classification scheme. Specifically, this equation tells us that the $M_{j}$ or the total number of country $j$ ships entering the Home seaport in the time interval $[0, t]$ are independent Poisson distributed random variables with means $\lambda \int_{0}^{t} P_{j}(s) d s, j=1,2, \cdots, K$, respectively. This kind of ship classification scheme can be used by the Home seaport manager to create non-uniform inspection protocols that can form part of the basis for efficient differential regulatory treatment regimes. Now, inspection protocols are costly to design and implement. Therefore, in the face of pressing budget constraints - see Kaufman (2004) - an organization such as the United States Department of Agriculture's Animal and Plant Health Inspection Service (APHIS) would be very interested in determining the total cost of inspecting the ships that arrive in the Home seaport during the time interval $[0, t]$. As such, we now address this inspection cost question.

\section{Total Cost of Inspections}

\subsection{Compound Poisson random variables and processes}

Generalizing from the discussion in section 2.1 , let $X_{1}, X_{2}, X 3, \cdots$ be a sequence of independent and identically distributed random variables with cumulative distribution function $F($.). Suppose that this sequence of random variables is independent of a Poisson distributed random variable denoted by $M$, with mean $\lambda>0$. Then, following Ross $(1996$, p. 82$)$, the random variable $W=\sum_{i=1}^{M}$ $X_{i}$ is a compound Poisson random variable with parameter $\lambda>0$ and component cumulative distribution function $F($.).

Finally, following Ross (1996, p. 87), the stochastic process $\{X(t): t \geq 0\}$ is said to be a compound Poisson process if, for $t \geq 0$, this process can be represented as $X(t)=\sum_{i=1}^{M(t)} X_{i}$ where $\{M(t): t \geq 0\}$ is a Poisson process and $\left\{X_{i}, i=1,2,3, \cdots\right\}$ is a collection of independent and identically distributed random variables that is independent of the Poisson process $\{M(t): t \geq 0\}$. Given this definition, it should be clear to the reader that if $\{X(t): t \geq 0\}$ is a compound Poisson process then $X(t)$ is a Poisson random variable. The outstanding task before us now is to ascertain the total cost of inspecting the ships that arrive in the Home seaport during the time interval $[0, t]$.

\subsection{A stochastic total inspection cost metric}

As in section 2.2, assume that ships arrive at the Home seaport under study in accordance with a Poisson process with rate $\lambda>0$. To account for the heterogeneity in actual ship inspection costs, we suppose that for a ship entering the Home seaport at time $s$, the cost incurred to inspect this ship is a random amount (in, say, dollars) and this random inspection cost amount has a cumulative distribution function $F_{s}(),. s \geq 0 .{ }^{6} \quad$ Our goal now is to shed light on $T C$ where $T C$ is the sum of all the random ship inspection costs that are incurred by time $t$.

We claim that $T C$ is a compound Poisson random variable. To prove this, we have to show that $T C$ has the same properties as the random variable $W$ in section 3.1. Put differently, we have to demonstrate that $T C$ has the same distribution as $\sum_{i=1}^{M} X_{i}$ where the $X_{i}$ are independent and identically distributed random variables that are independent of $M$, a Poisson distributed random

\footnotetext{
${ }^{6}$ We have two kinds of heterogeneity in mind in this note. The first kind is the inter-country heterogeneity. This stems from the fact that the ships entering the Home seaport are from different countries and the likelihood of unintentional alien species introductions from these different countries is not identical. The second kind is the intra-country heterogeneity. This arises from the fact that ships-even if they are from the same country-are entering the Home seaport at different points in the time interval $[0, t]$ and hence the risks of unintentional alien species introductions are dissimilar. To see this concretely, consider two ships arriving in the Home seaport from the same country. The first ship may have taken on ballast water in the ocean during an algal bloom and the second ship may not have done so. This means that the risk of inadvertent alien species introductions from these two ships-that are from the same country-is different.
} 
variable.

To prove the above claim, let us begin by letting $C_{i}$ be the random cost of inspecting the $i t h$ ship. $^{7} \quad$ Now, conditioning on $M(t)$ (see section 3.1), we get

$$
\operatorname{Prob}\{T C \leq x\}=\sum \forall m \operatorname{Prob}\left\{\sum_{i=1}^{M(t)} C_{i} \leq x / M(t)=m\right\} \cdot e^{-\lambda t}(\lambda t)^{m} / m ! .
$$

Given that $M(t)=m$ and using theorem 2.3.1 in Ross (1996, p. 67), we reason that the unordered ship arrival times are independent and uniformly distributed random variables in the time interval $[0, t]$. This last result allows us to simplify the RHS of equation (4). This simplification yields

$$
\operatorname{Prob}\left\{\sum_{i=1}^{M(t)} C_{i} \leq x / M(t)=m\right\}=\operatorname{Prob}\left\{\sum_{i=1}^{m} X_{i} \leq x\right\},
$$

where the are $X_{i}$ independent random variables with

$$
\operatorname{Prob}\left\{X_{i} \leq x\right\}=(1 / t) \int_{0}^{t} F_{s}(x) d s .
$$

Equations (4) - (6) together tell us that the random variable $T C$ can be expressed as $T C=\sum_{i=1}^{M}$ $X_{i}$, where $M$ is Poisson distributed with mean $\lambda t$ and the $X_{i}$ are independent random variables with cumulative distribution function given by equation (6). In other words, we have now proved that the total cost of inspecting the ships entering the Home seaport in the interval $[0, t]$ is a compound Poisson random variable. This finding can be used by the manager of the Home seaport in two ways. First, the manager can use this finding to compare the magnitudes of his or her apportioned inspection budget with actual inspection costs that are incurred in a particular time period of interest. Second, this manager can also use this finding to formulate an objective function that would then be optimized to ensure an efficient allocation of inspection resources.

Before concluding this section, we would like to reiterate that the modeling framework of this note is based fundamentally on the notion that different countries-and hence the ships coming from these different countries-are dissimilar as far as the likelihood of unintentional alien species introductions are concerned. This is the main reason for first providing a particular way of classifying the ships that enter the Home seaport from the $K$ different countries and then characterizing the total cost of inspecting the ships that arrive in this seaport. Put differently, we are neither advocating nor studying the use of "blind" inspection policies that ignore country-specific information about the likelihood of one or more biological invasions.

\section{Conclusions}

In this note, we used a dynamic and stochastic framework to shed light on two insufficiently studied theoretical questions concerning alien species management in an arbitrary seaport in a

\footnotetext{
${ }_{7}$ The reader should interpret these $C_{i}^{\prime} s$ as the dependent variables that emerge from a cost function in which the independent variable is the actual inspection effort. In addition, the reader should also keep in mind that we are working with a dynamic and stochastic framework in which - as explained in footnote 6 -here are two kinds of heterogeneity. Operationally, this means that the actual inspection effort will typically vary from ship to ship and hence will be random. Further, because the $C_{i}^{\prime} S$ depend on the actual inspection effort which is random, they themselves are random. In this note, we are not interested in determining the optimal inspection effort. However, if we were interested in doing so then the following three points would need to be considered. First, in a deterministic setting, we could choose the inspection effort to, for instance, minimize the total cost of conducting inspections. Second, in a stochastic framework, it would not make much sense to choose the random inspection effort. In such a setting, one could choose the mean inspection effort to, for instance, minimize the total cost of conducting inspections. Finally, if we wanted to stress what the seaport manager learned about the two kinds of heterogeneity delineated in footnote 6 while conducting inspections then we would want to introduce a Bayesian learning framework in which the mean inspection effort would be a function of an updated probability and the updating would concern what was learned about the likelihood of a biological invasion in a previous inspection of one or more ships from the $K$ possible countries.
} 
country called Home. First, we provided a specific way of classifying the ships that entered the Home seaport from $K$ potential countries in the time interval $[0, t]$. Second, we characterized the total cost of inspecting the ships that arrived in the Home seaport during the same time interval $[0$, $t]$.

The analysis in this note can be extended in a number of different directions. In what follows, we suggest three possible extensions. First, it would be useful to use the findings in sections 2 and 3 to formulate objective functions that a Home seaport manager-interested in precluding the accidental introductions of one or more alien species-might optimize. Second, with the goal of preventing unintentional biological invasions, it would be instructive to study the interaction between Home and its trading partners in a game-theoretic context. Finally, given the findings in section 3, it would be useful to study the properties of random inspection schemes in which the total cost of inspections satisfies a budget balance constraint. Studies that analyze these aspects of the problem will increase our understanding of the connections between international maritime trade and alien species management.

\section{References}

[1] Batabyal, A.A., "A Rationale for the Differential Regulatory Treatment of Imports When Invasive Species are a Potential Problem," Studies in Regional Science, 36, 2006, 179-187.

[2] Batabyal, A.A., "Two Theoretical Issues Concerning the Differential Treatment of Trading Partners in Alien Species Management," Ecological Economics, 64, 2008, 679-682.

[3 ] Batabyal, A.A., Beladi, H. and Koo, W.W., "Maritime Trade, Biological Invasions, and the Properties of Alternate Inspection Regimes," Stochastic Environmental Research and Risk Assessment, 19, 2005, 184-190.

[4] Batabyal, A.A. and Lee, D.M., "The Infinitesimal, the Deterministic, and the Probabilistic: Alternate Container Inspection Policies in Invasive Species Management," Biological Invasions, 8, 2006, 1663-1671.

[5 ] Batabyal, A.A. and Nijkamp, P., "The Stochastic Arrival of Alien Species and the Number of and the Damage from Biological Invasions," Ecological Economics, 62, 2007, 277-280.

[6 6 Costello, C. and McAusland, C., "Protectionism, Trade, and Measures of Damage from Exotic Species Introductions," American Journal of Agricultural Economics, 85, 2003, 964-975.

[ 7 ] Costello, C., Springborn, M., McAusland, C. and Solow, A., "Unintended Biological Invasions: Does Risk Vary by Trading Partner ?," Journal of Environmental Economics and Management, 54, 2007, 262-276.

[ 8 ] Cox, G.W., "Conservation Ecology. W.C. Brown Publishers, Dubuque, Iowa, 1993.

[9 9 DeAngelo, G.J., Batabyal, A.A. and Kumar, S., "An Analysis of Economic Cost Minimization and Biological Invasion Damage Control Using the AWQ Criterion," Annals of Regional Science, 41, 2007, 639-655.

[10] de Wit, M.P., Crookes, D.J. and van Wilgen, B.W., "Conflicts of Interest in Environmental Management: Estimating the Costs and Benefits of a Tree Invasion," Biological Invasions, 3, 2001, 167-178.

[11] Finoff, D., Shogren, J.F., Leung, B., and Lodge, D., "Take a Risk: Preferring Prevention Over Control of Biological Invaders," Ecological Economics, 62, 2007, 216-222.

[12] Kaufman, M., "FDA a Big Winner in 05 Bush Budget ; More Funds Sought for Food Security," Washington Post, February 6, 2004, p. A21.

[13] Levine, J.M. and D'ntonio, C.M., "Forecasting Biological Invasions With Increasing International Tandem," Conservation Biology, 17, 2003, 322-326.

[14] Levinson, M., The Box. Princeton University Press, Princeton, New Jersey, 2006.

[15] Mehta, S.V., Haight, R.G., Homans, F.R. and Polasky, S., "Optimal Detection and Control Strategies for Invasive Species Management,” Ecological Economics, 61, 2007, 237-245. 
[16] Office of Technology Assessment (OTA), Harmful Non-Indigenous Species in the United States. OTA-F-565, Washington, District of Columbia, 1993.

[17] Perrings, C., "Mitigation and Adaption Strategies for the Control of Biological Invasions," Ecological Economics, 52, 2005, 315-325.

[18] Pimentel, D., Lach, L., Zuniga, R. and Morrison, D., "Environmental and Economic Costs of Nonindigenous Species in the United States,” BioScience, 50, 2000, 53-65.

[19] Ross, S.M., Stochastic Processes, 2nd edition. Wiley, New York, New York, 1996.

[20] Savidge, J.A., "Extinction of an Island Forest Avifauna by an Introduced Snake," Ecology, 68, 1987, 660-668.

[21] Tijms, H.C., A First Course in Stochastic Models. Wiley, Chichester, UK, 2003.

[22] Vitousek, P.M., D’ntonio, C.M., Loope, L.L. and Westbrooks, R., "Biological Invasions as Global Environmental Change," American Scientist, 84, 1996, 468-478.

[23] Work, T.T., McCullough, D.G., Cavey, J.F. and Komsa, R., “Arrival Rate of Non-indigenous Insect Species inti the United States through Foreign Trade,” Biological Invasions, 7, 2005, 323332 . 